\title{
GUIDED IMAGERY DALAM ASUHAN NYERI HAID (DISMENORE) PRIMER PADA MAHASISWI D3 KEBIDANAN
}

\author{
${ }^{1)}$ Dewi Nurlaela Sari, ${ }^{2)}$ Deva Frisilya \\ Prodi D3 Kebidanan, Fakultas Ilmu Kesehatan, Universitas Bhakti Kencana \\ Jl. Soekarno-Hatta No.754 Cibiru-Bandung-Indonesia \\ Email : ${ }^{1)}$ dewi.nurlaela@ bku.ac.id, ${ }^{2)}$ frisilyadf@ gmail.com
}

Kata Kunci:

Dismenore, Guided Imagery, Menstruasi, Remaja
Keywords:

Dysmenorrhea, Guided

Imagery, Menstruation,

Teenagers)

\section{Info Artikel}

Tanggal dikirim: 19 Juni 2020 Tanggal direvisi: 23 Juli 2020

Tanggal diterima: 24 Juli 2020

DOI Artikel:

10.36341/jomis.v4i2.1357

Creative Commons AttributionNonCommercial-ShareAlike 4.0 International License.

\begin{abstract}
ABSTRAK
Masa peralihan dari masa kanak-kanak ke masa dewasa disebut masa remaja. Pada masa ini terjadi proses perubahan fisik maupun psikis yang terkadang menimbulkan gangguan. Perubahan fisik atau biologis pada remaja perempuan adalah mulai mengalami menstruasi. Salah satu keluhan yang biasanya terjadi pada perempuan yang sedang menstruasi adalah dismenore. Guided imagery adalah salah satu teknik relaksasi yang berfungsi untuk mengurangi nyeri. Penelitian ini bertujuan untuk mengetahui apakah terdapat pengaruh terapi relaksasi guided imagery dengan penurunan tingkat nyeri dismenore primer pada Mahasiswi D3 Kebidanan. Jenis metode adalah quasy eksperiment dengan one group pre-post test design. Teknik pengambilan sampel yaitu total sampling dengan 51 responden. Instrumen yang digunakan adalah NRS (numeral rating scale) dan SOP terapi guided imagery. Jenis analisa univariat menggunakan distribusi frekuensi dan analisa bivariat menggunakan analisis uji paired $t$ test. Hasil penelitian menunjukkan intervensi yang dilakukan efektif terlihat dari skala nyeri haid dapat menurun dengan relaksasi guided imagery dengan hasil $p$-value (2-tailed) 0,000 ( $\mathrm{p}<0,05)$. Simpulan didapatkan adanya pengaruh yang signifikan terapi relaksasi guided imagery terhadap penurunan tingkat nyeri haid (dismenore) pada Mahasiswi D3 Kebidanan. Berdasarkan penelitian diatas, relaksasi guided imagery dapat diterapkan sebagai salah satu penanganan nyeri secara non farmakologi saat menstruasi (dismenore).
\end{abstract}

\begin{abstract}
The transition from childhood to adulthood is called adolescence. During this time a process of physical and psychological change that occurs disruption. Physical or biological changes in adolescent girls are beginning to increase menstruation. One complaint that usually occurs in women who are menstruating is dysmenorrhea. Guided imagery is a relaxation technique that works to reduce pain. D3 Midwifery. This type of method is an easy experiment with one group pre-post test design. The sampling technique is total sampling with 51 respondents. The instruments used were $N R S$ (numeral rating scale) and guided imagery therapy SOP. The type of univariate analysis uses frequency distribution and bivariate analysis uses paired t-test analysis. The results showed effective interventions seen from the scale of menstrual therapy can decrease with guided relaxation of the image with the results of the p-value (2tailed) 0,000 ( $p$ <0.05). Conclusions obtained from the significant influence of the imaging-guided relaxation of decreased levels of menstrual pain (dysmenorrhea) in D3 Midwifery Students. Based on the above research, images guided relaxation can be applied as one of the non-pharmacological treatments during menstruation (dysmenorrhea).
\end{abstract}




\section{PENDAHULUAN}

Masa remaja merupakan masa transisi dari anak-anak menuju dewasa. Mahasiswi termasuk salah satu tingkatan usia yang ada pada periode remaja Masa ini ditandai dengan perubahan fisik dan psikis yang kompleks dan dinamis disertai penyesuaian sosial untuk menjadi dewasa [1]

Percepatan pertumbuhan merupakan indikator perubahan fisik remaja. Menstruasi merupakan salah satu perubahan fisik/biologis pada remaja perempuan [2]

Menstruasi merupakan proses alamiah yang terjadi pada siklus reproduksi seorang perempuan. Menstruasi ini sering disertai dengan beberapa masalah atau keluhan, yakni salah satunya adalah nyeri pada saat menstruasi atau dismenore [3]

Dismenore merupakan nyeri yang

dirasakan pada hari pertama sampai kedua menstruasi. Rasa nyeri ini desebabkan oleh kontraksi otot uterus yang terus menerus. Nyeri yang dirasakan bahkan seringkali mengharuskan penderita mengkonsumsi obatobatan pereda nyeri, beristirahat, bahkan meninggalkan aktivitasnya. Diperkirakan sekitar 50\% wanita di dunia mengalami dismenore, sedangkan di Indonesia yaitu sekitar $64,25 \%$ yang terdiri dari $54,89 \%$ dismenore primer dismenore sekunder sebanyak 9,36\%. Beberapa penelitian salah satunya dari Pusat Informasi dan Konseling Kesehatan Reproduksi Remaja (PIK-KRR) menyebutkan bahwa kejadian dismenore berkisar $45-95 \%$ dikalangan usia produktif, terdiri dari $72,84 \%$ dismenore primer dan $27,11 \%$ dismenore sekunder [4]. Kejadian Dismenore di Jawa Barat cukup tinggi, yaitu sebanyak $54,9 \%$ terdiri dari $24,5 \%$ dismenore ringan, 21,28\% mengalami dismenore sedang dan 9,36\% mengalami dismenore berat [5].

Perbedaan Dismenore primer dengan dismenore sekuder yaitu bahwa pada dismenore sekunder nyeri yang ditimbulkan akibat adanya kelainan anatomis pada daerah uterus atau rongga panggul. Sementara untuk derajat nyeri dismenore dapat dibedakan menjadi dismenore ringan, sedang dan berat yang dapat dilihat dari gejala yang ditimbulkan [6].

Sebagian besar remaja merupakan pelajar, atau mahasiswi, jika mereka mengalami dismenore kemungkinan besar aktivitas belajar mereka akan terganggu atau bahkan tidak masuk sekolah atau kuliah. Seorang mahasiswi tidak akan berkonsentrasi belajar, motivasi belajar menurun atau bahkan harus meminta izin untuk pulang atau istirahat di UKS karena tidak tahan terhadap nyeri yang dirasakan pada saat mengalami dismenore.[7]

Banyak cara yang dapat dilakukan untuk menurunkan atau mengurangi nyeri saat menstruasi, namun saat ini upaya yang dilakukan terbatas pada terapi farmakalogi yaitu dengan pemberian obat pereda nyeri dibandingkan dengan terapi non farmakologi yang tidak memiliki efek samping karena pengaruh konsumsi obat terus menerus.

Exercise/latihan (olahraga), massage, relaksasi, mandi air hangat, meletakan botol yang berisi air hangat di perut, minum ramuan tradisional dan menghindari merokok merupakan jenis terapi non farmakologi yang dapat dilakukan untuk mengatasi dismenore [3]

Terapi relaksasi dapat menjadi salah satu pilihan dan dapat diterapkan pada remaja putri khususnya mereka yang merupakan pelajar/ mahasiswi. Hal tersebut disebabkan karena pada tahapan ini secara psikologis mereka belum stabil emosional, keinginan untuk meniru, mendapatkan penghargaan yang tinggi sehingga dengan refleksi akan memudahkan untuk mencapai pola psikologis tersebut. Hal ini sejalan dengan penelitian yang dilakukan Lis, dkk mengenai konsep diri remaja Seorang remaja berusaha mencapai kepuasan baik pribadi maupun perasaan efektif dengan cara mencari aktivitas dan umpan balik yang mempertinggi konsep diri [4]. Guided imagery termasuk teknik relaksasi, dimana relaksasi guided imagery relaksasi dengan memberikan imajinasi terbimbing. Relaksasi ini dapat menghilangkan nyeri dengan membentuk bayangan atau imajinasi sesuai arahan dari seorang guide yang melibatkan berbagai indera, sehingga dengan membayangkan 
sesuatu yang indah akan merasa tenang dan nyaman. Relaksasi tersebut juga merangsang hormon endorphin sehingga akan melakukan blocking atau menggantikan ketegangan otot dan ketidaknyamanan yang dirasakan[8].

Terapi guided imagery memberikan manfaat untuk mengatasi kecemasan, stres, dan nyeri dari interevensi perilaku yang dilakukan [9]. Hal ini dapat dijelaskan denga konsep pengkondisian klaik yakni reaksi dan stimulus yang ditimbulkan tergantung dari imajinasi mengenai pengalaman yang menyenangka. Perpaduan antara satu stimulus dengan stimulus lainnya akan menimbulkan suatu pengkondisian. Begitupun dengan nyeri dismenore, ketika seorang remaja mengalami nyeri dismenore maka respon yang ditimbulkan adalah sensasi dismenore. Tetapi ketika seorang remaja mengalami dismenore sementara stimulus yang dimunculkan hal atau perasaan yang menyenangkan maka reaksi yang timbul adalah perasaan senang. Sehingga dengan stimulus perasaan menyenangkan yang terus menerus, perasaan nyeri yang diakibatkan dismenore akan merubah sensansi nyeri bahkan menghilang.

\section{TINJAUAN PUSTAKA}

Nyeri haid (dismenore) merupakan nyeri pada daerah perut akibat kontraksi atau kejang otot uterus yang terjadi menjelang atau selama haid yang dapat mengganggu aktivitas seharihari wanita. Banyak cara yang dapat dilakukan untuk menurunkan atau mengurangi nyeri saat menstruasi, baik secara farmakologi ataupun secara non fakmakologi. Namun manajemen non farmakologi lebih aman digunakan karena tidak menimbulkan efek samping. Beberapa cara non farmakologi yang dapat dilakukan untuk mengatasi dismenore diantaranya mandi air hangat, meletakan botol yang berisi air hangat di perut, massage, relaksasi, exercise/latihan (olahraga), minum ramuan tradisional dan menghindari merokok [6].

Manajemen nyeri dengan melakukan teknik relaksasi merupakan tindakan eksternal yang mempengaruhi respon internal individu terhadap nyeri. Salah satu tehnik relaksasi non farmakologi yang dapat dilakukan adalah guided imagery yaitu suatu proses yang menggunakan kekuatan pikiran dan memelihara kesehatan atau rileks melalui komunikasi dalam tubuh melibatkan semua indera [8].

Guided imagery suatu tehnik yang menuntut seseorang untuk membentuk sebuah bayangan/imajinasi tentang hal-hal yang disukai. Imajinasi yang terbentuk akan diterima sebagai rangsang oleh alat indera, kemudian rangsangan tersebut akan dijalankan ke batang otak menuju sensor thalamus. Di thalamus rangsang di diformat sesuai dengan bahasa otak, sebagian kecil rangsangan itu transmisikan ke amigdala dan hipokampus sekitarnya dan sebagian besar lagi dikirim ke korteks serebri, kemudian di korteks serebri terjadi proses asosiasi penginderaan dimana rangsangan di analisis, dipahami dan disusun menjadi sesuatu yang nyata sehingga otak mengenali objek dan arti kehadiran tersebut [14].).

Hipotalams berperan sebagai penentu sinyal sensorik dianggap penting atau tidak sehingga jika hipokampus memutuskan sinyal tersebut akan disimpan sebagai ingatan. Halhal yang disukai dianggap sebagai sinyal penting oleh hipotalamus sehingga diproses sebagai memori. Ketika terdapat rangsangan berupa bayangan tentang hal-hal yang disukai tersebut, memori yang telah tersimpan akan muncul kembali dan menimbulkan suatu persepsi dari pengalaman sensasi yang sebenarnya, walaupun pengaruh atau akibat yang timbul hanyalah suatu memori dari suatu sensasi [14].

Melalui relaksasi nafas dalam secara perlahan akan meningkatkan enkephalin dan endorphin dan dengan adanya rangsangan berupa bayanagn tentang hal-hal yang disukai, akan merasa lebih rileks dan nyaman [7].

\section{METODE}

Quasy eksperiment merupakan metode penelitian yang digunakan dengan pendekatan one group pre-post test design. Tujuannya, untuk menguji hubungan sebab-akibat terhadap suatu perlakuan atau intervensi. Penelitian ini dilakukan dengan cara 
mengelompokkan responden atau subjek lalu di observasi pada saat sebelum dan sesudah intervensi (guided imagery) dilakukan [10].

Mahasiswi D3 Kebidanan merupakan populasi penelitian ini dengan sample sebanyak 51 responden. Pengambilan sampel dilakukan dengan teknik purposive sampling yang didasarkan pada suatu pertimbangan tertentu berdasarkan ciri atau sifat-sifat populasi yang sudah diketahui sebelumnya [11]. Intensitas nyeri haid di ukur menggunakan Numeral Rating Scale (NRS) sebelum dan setelah intervensi dilakukan. Uji bivariat yang digunakan adalah uji wilxocon dengan paired $t$ test. Instrumen yang digunakan dalam penelitian ini adalah lembar pengukuran tingkat nyeri dan SOP terapi relaksasi guided imagery.

\section{HASIL DAN PEMBAHASAN}

Berdasarkan penelitian yang dilakukan terhadap 51 responden pada Mahasiswi D3 Kebidanan. Didapatkan hasil sebagai berikut.

\section{Tabel 1}

Tingkat Nyeri Haid pada Mahasiswi D3 Kebidanan Sebelum dilakukan Intervensi

\begin{tabular}{cccc}
\hline No & Tingkat Nyeri & $\begin{array}{c}\text { Frekuensi } \\
\text { Pre-test }\end{array}$ & $\begin{array}{c}\text { Presentasi } \\
(\%) \\
\text { Pre-test }\end{array}$ \\
\hline 1. & Tidak Nyeri & 0 & $0 \%$ \\
2. & Nyeri Ringan & 0 & $0 \%$ \\
3. & Nyeri Sedang & 27 & $52,9 \%$ \\
4. & Nyeri Berat & 24 & $47,1 \%$ \\
\hline & Total & $\mathbf{5 1}$ & $\mathbf{1 0 0 \%}$ \\
\hline
\end{tabular}

Berdasarkan tabel 1 dapat diketahui bahwa sebagian besar responden mengalami nyeri sedang saat haid (dismenore) sebelum dilakukan terapi relaksasi guided imagery dengan jumlah responden sebanyak 27 Mahasiswi(52,9\%).

Nyeri haid (dismenore) merupakan keadaan nyeri yang di hadapi seorang wanita pada hari-hari pertama menstruasi nya yang diakibatkan oleh kontraksi otot uterus. Hal tersebut dapat menimbulkan masalah khusunya untuk pelajar atau mahasiswi dalam menjalankan aktivitas belajaranya. Nyeri haid (dismenore) dirasakan akibat dari peningkatan hormon prostaglandin yang mengakibatkan hipertonus dan vasokontriksi miometrium sehingga terjadi iskemi dan nyeri pada perut bagian bawah. [7].

Berdasarkan hasil analisis peneliti mengenai banyaknya mahasiswi yang mengalami nyeri berat sebanyak 24 orang $(47,1 \%)$ pada penelitian ini dapat diakibatkan oleh beberapa faktor. Yakni, dilihat dari sifat nyeri itu sendiri yang bersifat subjektif, artinya seseorang bisa merasaka nyeri yang berat sementara beberapa orang lainnya hanya merasakan nyeri ringan dalam kondisi yang sama. Selain sifat nyeri faktor lain yang mempengaruhi yaitu usia pada saat menarche (haid pertama). Beberapa penelitian menunjukkan bahwa seorang wanita yang mengalami menarche pada usia $<11$ tahun memiliki resiko 3,4 lebih besar mengalami dismenore primer dibandingkan dengan wanita yang mengalami menarche pada usia $>11$ tahun. Usia menarche yang dini memiliki konsentrasi estradiol yang lebih tinggi sedangkan hormon testosteron dan dehidroepiandosteron lebih tinggi. Pada penelitian ini usia Mahasiswi pada saat menarche yaitu 10-14 tahun.

Faktor lain yang mempengaruhi Mahasiswi mengalami nyeri berat saat menstruasi yaitu olahraga. Diakui dari sebagian besar responden mengatakan bahwa jarangnya melakukan olahraga dan hanya melakukan olahraga ketika ada jadwal olahraga dari kampus. Olahraga yang teratur dapat meningkatkan kadar oksigen dan sirkulasi darah menuju uterus menjadi lancar sehingga dapat mengurangi dismenore. Selain itu, olahraga yang rutin juga dapat meningkatkan produksi hormon endorphin sehingga rasa tegang dan nyeri dapat berkurang [12]. Selain itu, status gizi mahasiswa juga dapat menjadi faktor dismenore itu sendiri. 87\% mahasiswa D3 Kebidanan tidak tinggal bersama orang tuanya, yaitu asrama dan kos. Hal ini, menyebabkan asupan nutrisi mahasiswa terbatas dengan harus mencari sendiri tidak disediakan seperti mereka dirumah. Berdasarakan Keputusan 
Mentri Kesehatan Tahun 2010 tentang standar antropometri penilaian status gizi pada anak dan remaja, Penilaian status gizi dihitung berdasarkan Indeks Masa Tubuh (IMT)/Umur (U) yang dikatagorikan menjadi sangat kurus, kurus, normal, gemuk dan obesitas. Mahasiswi yang mempunyai status gizi gemuk dan obesitas akan meningkatkan resiko untuk terjadinya dismenore karena terdapat jaringan yang berlebihan yang mengakibatkan penebalan dinding rahim pembuluh darah pada organ reproduksi wanita sehingga menyebabkan terganggunya aliran menstruasi. Sedangkan untuk status gizi kurang akan mempengaruhi pertumbuhan dan fungsi organ tubuh juga akan menyebabkan terganggunya fungsi reproduksi termasuk timbulnya gangguan pada saat haid yaitu dismenore ini [13].

\section{Tabel 2}

\begin{tabular}{|c|c|c|c|}
\hline No & $\begin{array}{c}\text { Tingkat } \\
\text { Nyeri }\end{array}$ & $\begin{array}{c}\text { Frekuen } \\
\text { si } \\
\text { Post-test }\end{array}$ & $\begin{array}{c}\text { Presentase } \\
(\%) \\
\text { Post-test }\end{array}$ \\
\hline 1. & $\begin{array}{l}\text { Tidak } \\
\text { Nyeri }\end{array}$ & 5 & $9,8 \%$ \\
\hline 2. & $\begin{array}{c}\text { Nyeri } \\
\text { Ringan }\end{array}$ & 36 & $70,6 \%$ \\
\hline 3. & $\begin{array}{c}\text { Nyeri } \\
\text { Sedang }\end{array}$ & 10 & $19,6 \%$ \\
\hline 4. & $\begin{array}{l}\text { Nyeri } \\
\text { Berat }\end{array}$ & 0 & $0 \%$ \\
\hline & Total & 51 & $100 \%$ \\
\hline
\end{tabular}

Berdasarkan Tabel 2 dapat diketahui bahwa sebagian besar responden mengalami nyeri ringan setelah dilakukan terapi relaksasi guided imagey Dari 51 responden, 17 orang $(33,3 \%)$ diantaranya mengalami penurunan dari skala nyeri berat menjadi nyeri ringan, dan 5 orang $(11,8 \%)$ yang nyeri sedang mengalami penurunan menjadi tidak nyeri.

Guided imagery dapat menurunkan nyeri karena terapi ini memberikan efek rileks dengan menurunkan ketegangan otot. Pada saat keadaan tubuh nyaman dan rileks maka secara alamiah memicu pengeluaran hormon endorfin. Hormon ini memberikan efek pereda nyeri (analgesik) alami dari tubuh[14].

Penurunan tingkat nyeri yang terjadi disebabkan karena remaja putri merasakan efek relaksasi dan tenang saat berimajinasi dan sejenak melupakan rasa nyeri haid (dismenore) yang sedang dirasakan. Remaja putri juga mampu berkonsentrasi dengan baik saat pemandu melakukan bimbingan.

Tabel 3

Pengaruh Terapi Relaksasi Guided Imagery

Terhadap Penurunan Tingkat Nyeri Haid

(Dismenore) Pada Mahasiswi D3 Kebidanan

\begin{tabular}{|c|c|c|c|c|c|}
\hline \multirow{2}{*}{$\begin{array}{l}\text { Tingkat } \\
\text { Nyeri }\end{array}$} & \multicolumn{2}{|c|}{ Pre Test } & \multicolumn{2}{|c|}{ Post Test } & \multirow{7}{*}{$\begin{array}{l}\text { Sig (2- } \\
\text { tailed) }\end{array}$} \\
\hline & $\mathrm{F}$ & $\%$ & $\mathrm{~F}$ & $\%$ & \\
\hline $\begin{array}{l}\text { Tidak } \\
\text { Nyeri }\end{array}$ & 0 & $0 \%$ & 5 & $9,8 \%$ & \\
\hline $\begin{array}{c}\text { Nyeri } \\
\text { Ringan }\end{array}$ & 0 & $0 \%$ & 36 & $70,6 \%$ & \\
\hline $\begin{array}{c}\text { Nyeri } \\
\text { Sedang }\end{array}$ & 27 & $52,9 \%$ & 10 & $19,6 \%$ & \\
\hline $\begin{array}{l}\text { Nyeri } \\
\text { Berat }\end{array}$ & 24 & $47,1 \%$ & 0 & $0 \%$ & \\
\hline Total & 51 & 100 & 51 & 100 & \\
\hline
\end{tabular}

Berdasarkan Tabel 3, diketahui bahwa setelah dilakukan intervensi terapi relaksasi guided imagery terdapat penurunan tingkat nyeri. Dari total sampel 51 orang sebelum dilakukan terapi relaksasi guided imagery tersebar menjadi nyeri sedang 27 orang $(52,9 \%)$ dan nyeri berat sebanyak 24 orang $(47,1 \%)$. Hasil penelitian, dari 27 responden yang mengalami nyeri sedang mengalami penurunan tingkat nyeri menjadi 5 orang $(11,8 \%)$ mengalami tidak nyeri, 18 orang $(35,2 \%)$ mengalami nyeri ringan, dan 3 orang lainnya $(5,9 \%)$ masih di tingkat nyeri sedang. Berdasarkan hasil penelitian untuk 24 responden yang sebelumnya mengalami nyeri berat juga mengalami penurunan tingkat nyeri dimana diantaranya 17 orang $(33,3 \%)$ mengalami penurunan menjadi nyeri ringan, dan 7 orang lainnya $(13,8 \%)$ mengalami nyeri sedang.

Efek relaksasi yang ditimbulkan dari guided imagery ini menyebabkan perasaan rileks. Efek ini dilanjutkan ke hipotalamus dan 
menghasilkan hormon Corticotropin Releasing Factor (CRF). Hormon CRF akan merangsang kelenjar pituitari untuk meningkatkan Proopioidmelano Cortin (POMC) yang dapat menyebabkan produksi enkephalin oleh medulla adrenal meningkat. Selain itu, kelenjar pituitari juga menghasilkan endorpin sebagai neotransmitter yang dapat mempengaruhi suasana hati jadi rileks sehingga nyeri dismenore berkurang [14].

\section{KESIMPULAN}

Berdasarkan hasil penelitian yang telah dilakukan tentang terapi relaksasi guided imagery terdadap penurunan tingkat nyeri haid (dismenore) pada mahasiswi D3 Kebidanan, maka dapat diambil simpulan bahwa Terdapat pengaruh yang signifikan dalam pemberian terapi relaksasi guided imagery terhadap penurunan dismenore pada mahasiswi D3 Kebidanan dengan nilai signifikan $p$-value 0,000 .

\section{DAFTAR PUSTAKA}

[1] Efendi \& Makhfudli. Keperawatan Kesehatan Komunitas Teori dan Praktik dalam Keperawatan. Jakarta : Salemba Medika. 2009.

[2] Soetjiningsih. Buku Ajar Tumbuh Kembang Remaja dan Permasalahannya. Jakarta: Sagung Seto. 2010.

[3] Kusmiran. Kesehatan Reproduksi Remaja dan Wanita Edisi 2. Jakarta: Salemba. 2012.

[4] Proverawati A, Misaroh. Menarche : Menstruasi Pertama Penuh Makna. Yogyakarta : Nuha Medika. 2009.

[5] Madhubala, Jyoti K. Relation Between Dismenorrhea and body indexin adolescent with rural versus urban variation. The Journal of Obstetric and Gynecology of India. 2012. 62 (4): 442-5

[6] Cicilia, dkk. Hubungan Dismenore dengan Aktivitas Belajar Remaja Putri di SMA Kristen 1 Termohon. Program Studi Ilmu Keperawatan Fakultas Kedokteran Universitas Sam Ratulangi Manado. J Keperawatan. vol. 1 No 1. Pp 1-6. Aug. 2013.
[7] Grocke \& Moe.. Guided Imagery \& Music (GIM) and Music Imagery Methods for Individual and Group Therapy. London: Jessica Kingsley Publisher.2015.

[8] Gorman, B.. The Power of Guided Imagery. University of Minnesota : Mandala. 2010

[9] Nursalam. Metodologi Penelitian Ilmu Keperawatan Edisi 3. Jakarta: Salemba Medika. 2013.

[10] Notoatmodjo. Metodelogi Penelitian Kesehatan. Jakarta: Salemba Medika. 2018.

[11] Widyastuti, Yani, dkk. Kesehatan Reproduksi. Yogyakarta : Fitramaya. 2009.

[12]Daftaruy, patky. Reproductive Endocrinology \& Infertility. New Delhi : BI Publication Pvt ltd. 2009.

[13] Charu S, Amita R, dkk.. Menstrual Characteristics and prevalence and effect of dismenorrhea on quality of life of medical students. International Journal of Collaborative Research on Internal Medicine \& Public Helath. 4 (4):276-94. 2012

[14] John Hall. Guyton and Hall of Medical Physiology 12 th edition. Saunders: : elsyvier. 2010. 